\title{
Correction to: Aging and Mechanoadaptive Responsiveness of Bone
}

Behzad Javaheri $^{1} \cdot$ Andrew A. Pitsillides $^{1}$

Published online: 6 January 2020

(C) Springer Science+Business Media, LLC, part of Springer Nature 2020

\section{Correction to: Current Osteoporosis Reports} https://doi.org/10.1007/s11914-019-00553-7

The author missed to include the below statement in the Acknowledgement of the original article.

"This study was supported by funding from BBSRC BB/ I014608/1, Arthritis Research UK 20581”.

The online version of the original article can be found at https://doi.org/ 10.1007/s11914-019-00553-7

$\triangle$ Andrew A. Pitsillides apitsillides@rvc.ac.uk

1 Skeletal Biology Group, Comparative Biomedical Sciences, The Royal Veterinary College, Royal College Street, London NW1 0TU, UK 